\title{
Clonal Subgroup
}

National Cancer Institute

\section{Source}

National Cancer Institute. Clonal Subgroup. NCI Thesaurus. Code C96960.

A population of cells or organisms that are identifiable by specific, shared characteristics and presumed to have originated from a single progenitor. 